\title{
Accumulation of T-helper 22 cells, interleukin-22 and myeloid-derived suppressor cells promotes gastric cancer progression in elderly patients
}

\author{
XUEHUA CHEN, YANFU WANG, JIALI WANG, JINHUI WEN, XUZHAO JIA, XIAOJUN WANG and HUA ZHANG \\ Department of Geratology, The First Affiliated Hospital, Dalian Medical University, Dalian, Liaoning 116000, P.R. China
}

Received September 3, 2016; Accepted July 27, 2017

DOI: $10.3892 / 01.2018 .8612$

\begin{abstract}
Chronic inflammation and immunosuppression lead to aging and tumorigenesis. T-helper 22 (Th22) cells, interleukin 22 (IL-22) and myeloid-derived suppressor cells (MDSCs) serve an important role in inflammatory-immune diseases and cancer. However, the status of Th22 cells, IL-22 and MDSCs in aging and elderly gastric cancer progression is unknown. In the present study, 39 elderly patients with gastric cancer (EGC), 32 elderly healthy controls (HE) and 31 young healthy controls (HY) were enrolled, and the peripheral Th22, Th17 and Th1 cells, and MDSCs, were examined using flow cytometry. Plasma levels of IL-22, IL-6 and tumor necrosis factor- $\alpha$ (TNF- $\alpha$ ) were examined using ELISA. IL-22 protein levels in tumor tissues were examined using immunohistochemistry. There were increased numbers of peripheral Th22 and Th17 cells, and MDSCs, as well as increased plasma levels of IL-22, IL-6 and TNF- $\alpha$ in EGC compared with HE and HY. However, HE exhibited significantly increased levels of peripheral Th22 and Th17 cells as well as IL-6 and TNF- $\alpha$ compared with HY. Immunohistochemical analysis demonstrated that IL-22 protein accumulated in tumor cells and lymphocytes in the tumor microenvironment. The results obtained demonstrated that peripheral Th22 and Th17 cells as well as IL-6 and TNF- $\alpha$ plasma levels increased with aging. Furthermore, Th22 and Th17 cells, MDSCs, and IL-22 may be used as prognostic markers for identifying gastric cancer in elderly patients.
\end{abstract}

\section{Introduction}

A previous study has demonstrated that chronic low-grade inflammation is associated with aging and contributes to age-associated diseases (1). For example, cancer frequently

Correspondence to: Professor Hua Zhang, Department of Geratology, The First Affiliated Hospital, Dalian Medical University, 193 Lianhe Road, Dalian, Liaoning 116000, P.R. China E-mail: zhanghua2233@126.com

Key words: gastric cancer, aging, T-helper 22 cells, interleukin-22, myeloid-derived suppressor cells occurs in the elderly, which is associated with their inflammatory background (2). Recent advances have demonstrated that the balance of cluster of differentiation (CD) $4^{+} \mathrm{T}$ cell subsets and their cytokines serves an important role in maintaining inflammatory-immune homeostasis and tumorigenesis (3). In 2009, Eyerich et al (4) reported a new CD4 ${ }^{+}$ $\mathrm{T}$ cell subset, T-helper 22 (Th22) cells, which express C-C chemokine receptor 4 (CCR4), CCR6 and CCR10. Th22 cells mainly secrete interleukin 22 (IL-22), IL-13, IL-26 and tumor necrosis factor- $\alpha$ (TNF- $\alpha)(5)$. Th22 cell function is mainly exerted through the binding of IL-22 to its receptor (IL-10R2/IL-22R1) (6). Since IL-22R1 is selectively expressed by non-immune cells, particularly keratinocytes, gastrointestinal and respiratory epithelial cells (7), Th22 cells are considered as key cells which transmit the inflammatory signal to the surrounding tissues. Increased IL-22 levels in the circulation and tumor microenvironment have been identified in liver, gastric, colon and pancreatic cancer and are associated with tumor initiation and progression (8). Nevertheless, the exact underlying molecular mechanism of how IL-22 influences tumorigenesis remains unclear.

Th22 cells are similar to and have synergistic effects with Th17 cells in a variety of inflammatory-immune diseases (9). Th22 and Th17 cells express skin-homing receptors CCR4 and CCR10, and are regulated by IL-6, IL-1 and IL-23 $(10,11)$. We have previously demonstrated that the proportion of Th17 cells significantly increases with age and progression of colorectal cancer (12). In addition, the inflammatory aging factors IL- 6 and TNF- $\alpha$ are able to stimulate the transformation of naïve $\mathrm{CD}^{+} \mathrm{T}$ cells into Th22 cells $(13,14)$. These results suggest that Th22 cells may participate in aging and tumorigenesis.

Chronic inflammation and immune-suppression are often complementary (15). It has been suggested that accumulation of immune suppressor cells is one of the causes of immune system dysfunction in the elderly (16). Myeloid-derived suppressor cells (MDSCs) are an important type of immune suppressor cells (17). Various inflammation-associated factors including IL-6, TNF- $\alpha$ and IL-22 are able to induce MDSCs (18). Furthermore, MDSCs express IL-6, TNF- $\alpha$ and other cytokines to regulate inflammation and $\mathrm{CD}^{+} \mathrm{T}$ cell differentiation (19). However, the role for MDSCs in aging and tumorigenesis, and their association with Th22 cells, remains to be determined. 
Gastric cancer is an inflammation-associated type of cancer and is the third most common cause of cancer-related mortality worldwide. Furthermore, gastric cancer is also associated with age-related immunodeficiency (20). To explore the role of Th22 cells, IL-22 and MDSCs in aging and tumorigenesis, in the present study the levels of peripheral Th22, Th17 and Th1 cells, and MDSC, and plasma levels of IL-22, IL- 6 and TNF- $\alpha$ were determined in elderly patients with gastric cancer (EGC), elderly healthy controls (HE) and young healthy controls (HY).

\section{Materials and methods}

Subjects and samples. Fresh peripheral blood was obtained from EGC $(\mathrm{n}=39$; median age, 73 years; range, 65-91 years; male/female, 24:15) from The First Affiliated Hospital of Dalian Medical University, Dalian, China, between October 2014 and December 2015. The patients were histologically diagnosed. Patients receiving radiotherapy, chemotherapy or immunotherapy were excluded from the present study. Tumors were classified and staged according to the tumor-node-metastasis (TNM) classification system of the International Cancer Control/American Joint Committee on Cancer (Edition 7) (21). Of the 39 patients, 13 were classified as early stage (Stage I/II) and 26 were at advanced stage (Stage III/IV). In addition, fresh peripheral blood of HE $(n=32$; median age, 76 years; range, $65-90$ years; male/female, 16:16) and $\mathrm{HY}(\mathrm{n}=31$; median age, 27 years; range, 24-35 years; male/female, 14:17) were recruited from the Health Check-Up Center of The First Affiliated Hospital during the same period. Paraffin sections $(3-\mu \mathrm{m})$ from tumor tissues and non-tumor tissues $(>5 \mathrm{~cm}$ from the tumor lesion) were collected post-operatively from another 40 patients with gastric cancer (age range, 65-78 years). The clinical characteristics of the patients are summarized in Table I. The present study has been approved by the Ethics Committee of The First Affiliated Hospital of Dalian Medical University (Dalian, China), and written informed consent was obtained from each subject.

Flow cytometric analysis of Th1, Th17 and Th22 cells. Peripheral blood was collected from all subjects and cultured under stimulation conditions. Heparinized peripheral whole blood $(400 \mu 1)$ in an equal volume of RPMI-1640 medium (Tiangen Biotech Co., Ltd., Beijing, China) were incubated for $4 \mathrm{~h}$ at $37^{\circ} \mathrm{C}$ with $5 \% \mathrm{CO}_{2}$ in the presence of $25 \mathrm{ng} / \mathrm{ml}$ phorbol myristate acetate, $1 \mu \mathrm{g} / \mathrm{ml}$ ionomycin and $1.7 \mu \mathrm{g} / \mathrm{ml}$ monensin (all from Enzo Biochem, Inc., Farmingdale, NY, USA). Following incubation, the cells were fixed and permeabilized using FIX and PERM Reagent (MultiSciences Co., Ltd., Hangzhou, China), followed by staining with peridinin-chlorophyll-protein (PerCP)-cyanine (Cy) 5.5-conjugated anti-CD4 monoclonal antibody (cat. no., 45-0048-42; dilution,1:20; eBioscience; Thermo Fisher Scientific, Inc., Waltham, MA, USA) at room temperature in the dark for $30 \mathrm{~min}$. The cells were next stained with fluorescein isothiocyanate (FITC)-conjugated anti-interferon (IFN)- $\gamma$ (cat. no., 11-7319-82; dilution, 1:50), phycoerythrin (PE)-conjugated anti-IL-17 (cat. no., 12-7179-42; dilution, $1: 35$ ) and allophycocyanin (APC)-conjugated anti-IL-22 monoclonal antibodies (cat. no., 50-7229-42; dilution, 1:35) at room temperature in the dark for $25 \mathrm{~min}$ (all from eBioscience; Thermo Fisher Scientific, Inc.). Isotype controls [by staining with PerCP/Cy5.5-conjugated rat immunoglobulin G ( $\mathrm{IgG}) 2 \mathrm{a}$ (cat. no. 45-4321-80; dilution,1:20), FITC-conjugated rat IgG1 (cat. no. 11-4301-82; dilution, 1:50), PE-conjugated rat IgG1 (cat. no. 12-4301-82; dilution, 1:35), and APC-conjugated rat IgG1 (cat. no. 17-4301-82; dilution, 1:35) (all from eBioscience; Thermo Fisher Scientific, Inc.) at room temperature in the dark for corresponding time respectively] were used to enable correct compensation and confirm antibody specificity. Stained cells were analyzed by flow cytometric analysis using a FACSCalibur cytometer equipped with CellQuest software (version 5.2; BD Biosciences, Franklin Lakes, CA, USA).

Flow cytometric analysis of MDSCs. EDTA-anticoagulated peripheral whole blood was collected from all subjects. Blood $(100 \mu 1)$ was mixed with FITC-conjugated anti-human leucocyte antigen-antigen D-related (HLA-DR) (cat. no., 11-9952-41, 1:20), APC-conjugated anti-CD11b (cat. no., 17-0118-41; dilution; 1:20) and PE-Cy5-conjugated anti-CD33 monoclonal antibodies (cat. no., 15-0339-41; dilution, 1:20) (all from eBioscience; Thermo Fisher Scientific, Inc.), and incubated in the dark for $15 \mathrm{~min}$. Each sample was subsequently mixed with $1 \mathrm{ml}$ lysis buffer (Beyotime Institute of Biotechnology, Jiangsu, China) and subjected to flow cytometric analysis. In each case, staining was compared with that of the appropriately labeled isotype control antibody.

ELISA. Plasma was collected from peripheral blood via centrifugation at $1,500 \times \mathrm{g}$ at $4^{\circ} \mathrm{C}$ for $5 \mathrm{~min}$. Plasma IL-22, IL-6 and TNF- $\alpha$ levels were determined using an ELISA kit (MultiSciences Co., Ltd., Zhejiang, China), according to the manufacturer's protocol. The minimal concentration detection limit of IL-22, IL-6 and TNF- $\alpha$ was $2.56,0.37$ and $0.42 \mathrm{pg} / \mathrm{ml}$, respectively.

Immunohistochemistry. Paraffin sections, $(3-\mu \mathrm{m})$ from tissue specimens were deparaffinized by immersion in xylene (15 min $\mathrm{x} 2$ ), rehydrated using graded ethanol (anhydrous ethanol for $5 \mathrm{~min} \times 3,90 \%$ ethanol for $5 \mathrm{~min}, 80 \%$ ethanol for $5 \mathrm{~min}$ and $70 \%$ ethanol for $5 \mathrm{~min}$ ). Endogenous peroxidase activity was blocked with $3 \%$ hydrogen peroxide for $10 \mathrm{~min}$ at room temperature, followed by washes with PBS (5 $\mathrm{min} \times 3)$ and heated in citrate buffer $(10 \mathrm{mM}, \mathrm{pH} 6.0)$ at $100^{\circ} \mathrm{C}$ for $3 \mathrm{~min}$. This was followed by blocking with $50 \mu 15 \%$ bovine serum albumin (Sigma-Aldrich; Merck KGaA, Darmstadt, Germany) per paraffin section for $30 \mathrm{~min}$ at room temperature, followed by washes with PBS (5 min x3). Following blocking, the sections were incubated with anti-IL-22 antibody (cat. no; ab18499; 1:100; Abcam, Cambridge, UK) at room temperature for $1 \mathrm{~h}$, followed by incubation with anti-rabbit $\operatorname{IgG}$ secondary antibody (Boster Biological Technology, Pleasanton, CA, USA) at $37^{\circ} \mathrm{C}$ for $20 \mathrm{~min}$. Following a wash with PBS, staining was visualized with 3,3'-diaminobenzidine (Beyotime Institute of Biotechnology) as a chromogen at room temperature for $3 \mathrm{~min}$. All sections were counterstained with hematoxylin at room temperature for $1 \mathrm{~min}$ and viewed using a light microscope. Two independent investigators randomly selected 10 fields at x400 magnification and counted the proportion of stained cells. 
Table I. Association of IL-22 protein expression with clinicopathological data from elderly patients with gastric cancer.

\begin{tabular}{|c|c|c|c|c|c|c|c|}
\hline \multirow[b]{3}{*}{ Characteristic } & \multicolumn{6}{|c|}{ IL-22+ cells/total cells } & \multirow[b]{3}{*}{ P-value ${ }^{a}$} \\
\hline & \multicolumn{3}{|c|}{ Low infiltration } & \multicolumn{3}{|c|}{ High infiltration } & \\
\hline & $\mathrm{n}$ & $<1 \%$ & $1-5 \%$ & $5-10 \%$ & $\geq 10 \%$ & $\chi^{2}$ & \\
\hline Total & 40 & 4 & 15 & 14 & 7 & & \\
\hline Sex & & & & & & 0.345 & 0.457 \\
\hline Male & 31 & 4 & 12 & 11 & 4 & & \\
\hline Female & 9 & 0 & 3 & 3 & 3 & & \\
\hline Differentiation & & & & & & 0.150 & 0.755 \\
\hline Well-moderate & 16 & 2 & 5 & 6 & 3 & & \\
\hline Poor & 24 & 2 & 10 & 8 & 4 & & \\
\hline Depth of invasion & & & & & & 6.686 & $0.017^{\mathrm{a}}$ \\
\hline $\mathrm{T} 1+\mathrm{T} 2$ & 13 & 3 & 7 & 2 & 1 & & \\
\hline $\mathrm{T} 3+\mathrm{T} 4$ & 27 & 1 & 8 & 12 & 6 & & \\
\hline Lymph node metastasis & & & & & & 1.766 & 0.216 \\
\hline Negative & 23 & 2 & 11 & 9 & 1 & & \\
\hline Positive & 17 & 2 & 4 & 5 & 6 & & \\
\hline AJCC cancer stage & & & & & & 8.087 & $0.009^{\mathrm{a}}$ \\
\hline I-II & 16 & 1 & 11 & 2 & 2 & & \\
\hline III-IV & 24 & 3 & 4 & 12 & 5 & & \\
\hline Tumor size, cm & & & & & & 0.973 & 0.360 \\
\hline$\leq 5$ & 18 & 1 & 6 & 8 & 3 & & \\
\hline$>5$ & 22 & 3 & 9 & 6 & 4 & & \\
\hline
\end{tabular}

${ }^{\mathrm{a}} \mathrm{P}<0.05$. The $\chi^{2}$ test categorized the results into a low infiltration group (IL-22+ cells/total cells: $<1$ and $1-5 \%$ ) and a high infiltration group (IL-22+ cells/total cells: 5-10 and >10\%). AJCC, American Joint Committee on Cancer; IL, interleukin.

The results were categorized into four groups on the basis of the proportion of positive cells $(<1,1-5,5-10$ and $\geq 10 \%)$, with $>1 \%$ positive cells recorded as $(-), 1-5 \%$ positive cells recorded as $(+), 5-10 \%$ positive cells recorded as $(++)$, and $\geq 10 \%$ positive cells recorded as (+++); (-) and (+) were defined as low infiltration, and (++) and (+++) were defined as high infiltration. The association between the expression of IL-22 and the patient's sex, differentiation, depth of invasion, lymph node metastasis, cancer stage and tumor size were analyzed.

Statistical analysis. Data were analyzed using SPSS software (version 19.0; IBM Corp., Armonk, NY, USA) or GraphPad Prism software (version 5.0; GraphPad Software, Inc., La Jolla, CA, USA) and expressed as the mean \pm standard deviation. Comparisons between two groups were assessed using a non-paired Student's t-test. Comparison among the three different experimental groups was performed using one-way analysis of variance, and differences between two groups were determined using Newman-Keuls multiple comparison unless the data were not normally distributed, in which case a Kruskal-Wallis test and Nemenyi test were used. Correlation analysis was adopted for Pearson's or Spearman's correlation depending on data distribution. The quality of the data was analyzed using a $\chi^{2}$ test. $\mathrm{P}<0.05$ was considered to indicate a statistically significant difference.

\section{Results}

Flow cytometric analysis of Th22, Th17 and Th1 cells in patients with gastric cancer and healthy controls. Flow cytometric analysis was used to determine the distribution of Th22, Th17 and Th1 cells in EGC, HE and HY (Fig. 1). Th22, Th17 and Th1 cells were defined as CD4+IFN- $\gamma^{-}$IL-17-IL-22+, CD $4^{+}$IFN- $\gamma^{-}$IL-17 ${ }^{+}$IL-22- and $\mathrm{CD} 4^{+} \mathrm{IFN}-\gamma^{+}$, respectively.

The proportion of Th22 cells was significantly increased in HE compared with that in HY $(0.79 \pm 0.27$ vs. $0.36 \pm 0.21 \%$; $\mathrm{P}<0.001$; Fig. 1C and D). Furthermore, the proportion of Th22 cells was significantly increased in EGC compared with that in $\mathrm{HE}(1.16 \pm 0.33$ vs. $0.79 \pm 0.27 \%$; $\mathrm{P}<0.001$; Fig. $1 \mathrm{C}$ and $\mathrm{D})$. Similarly, Th17 cells were detected at an increased proportion in EGC compared with that in HE (2.91 \pm 0.93 vs. $2.24 \pm 0.79 \%$; $\mathrm{P}<0.001$; Fig. 1E). Furthermore, the proportion of Th17 cells was significantly increased in $\mathrm{HE}$ compared with that in HY (2.24 \pm 0.79 vs. $1.50 \pm 0.63 \%$; $\mathrm{P}<0.001$; Fig. 1E). However, no significant difference was observed in the distribution of Th1 cells between EGC and HE or HY groups (7.78 \pm 1.84 vs. $7.48 \pm 1.55$ or $7.65 \pm 1.60 \%$; P $>0.05$; Fig. $1 \mathrm{~F}$ ). In addition, the fraction of peripheral Th22 cells was increased in patients with advanced gastric cancer compared with patients with early-stage gastric cancer $(1.25 \pm 0.30$ vs. $0.98 \pm 0.32 \%$; $\mathrm{P}<0.05$; Fig. 1G) and Th17 (3.20 \pm 0.90 vs. $2.33 \pm 0.72 \%$; $\mathrm{P}<0.01$; Fig. $1 \mathrm{H})$. 

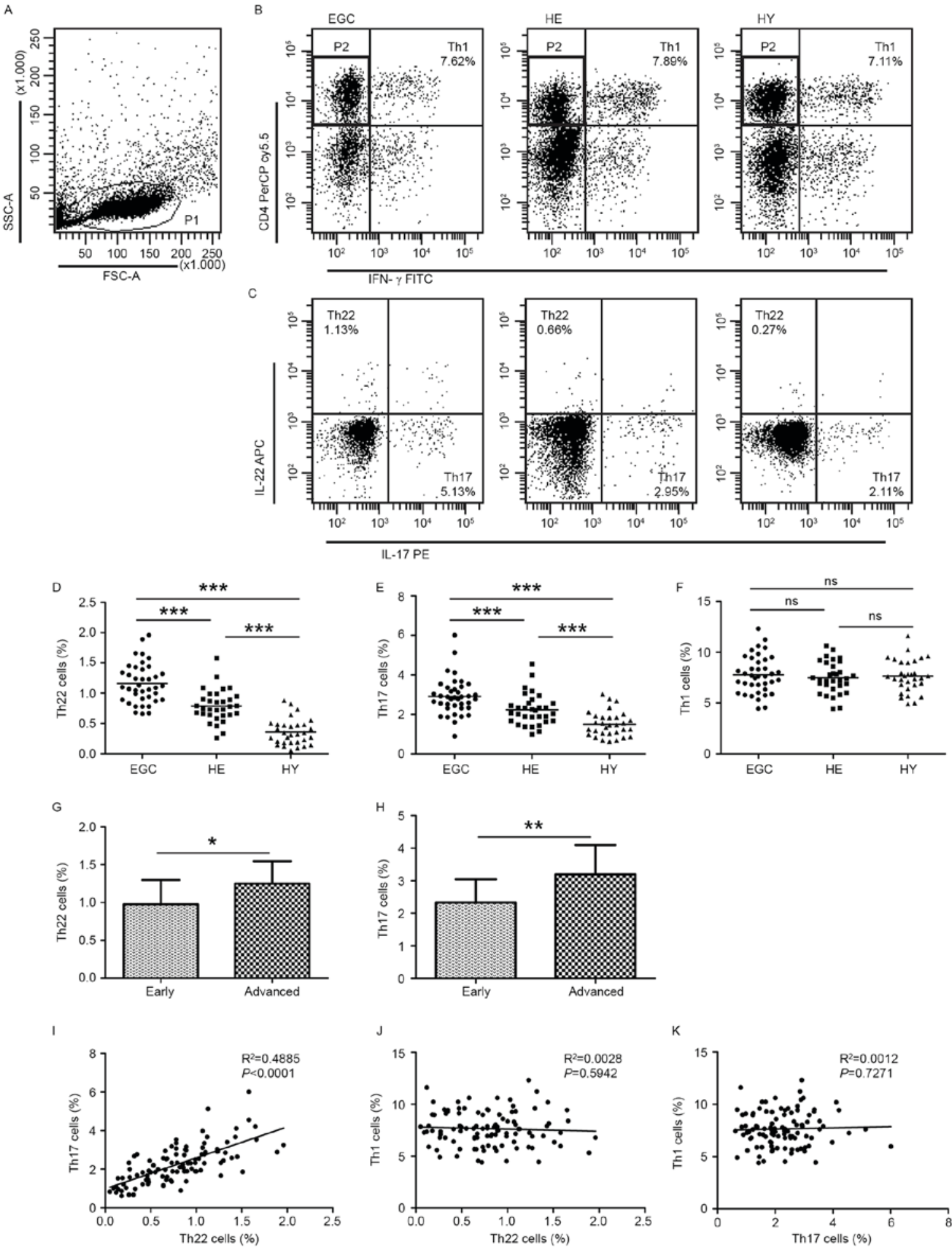

Figure 1. Flow cytometric analysis was used to determine the distribution of Th22, Th17 and Th1 cells in EGC, HE and HY (Fig. 1). Flow cytometric analysis of Th22, Th17 and Th1 cells in peripheral whole blood from EGC ( $\mathrm{n}=39)$, HE ( $\mathrm{n}=32)$ and $\mathrm{HY}(\mathrm{n}=31)$. (A) Lymphocytes were gated in P1 using flow cytometry. $\mathrm{CD} 4^{+} \mathrm{IFN}-\gamma^{-}$lymphocytes were gated in P2 using flow cytometry, and representative results of flow cytometric analyses for (B) Th1 (CD4 IFN- $\left.\gamma^{+}\right),(\mathrm{C}) \mathrm{Th} 22$ $\left(\mathrm{CD} 4{ }^{+}\right.$IFN- $\gamma$ IL-17-IL-22+) and Th17 (CD4+ IFN- $\gamma$ IL-17+IL-22-) cells in the three groups of subjects are presented. The number of cells stained in EGC, HE and HY in P2 were 2,654, 4,696 and 5,185, respectively. The proportion of (D) Th22, (E) Th17 and (F) Th1 cells in the three groups of subjects. The proportion of $(\mathrm{G})$ Th22 and $(\mathrm{H})$ Th17 cells in peripheral whole blood derived from patients with early $(\mathrm{n}=13)$ or advanced $(\mathrm{n}=26)$ gastric cancer. The association between the proportion of (I) Th22 and Th17 cells, (J) Th22 and Th1 cells, and (K) Th17 and Th1 cells, in peripheral whole blood of all subjects. ${ }^{*} \mathrm{P}<0.05$, ${ }^{* *} \mathrm{P}<0.01$, ${ }^{* * * *} \mathrm{P}<0.001$. ns, not significant; Th, T helper; EGC, elderly patients with gastric cancer; HE, elderly healthy patients; HY, young healthy patients; CD, cluster of differentiation; IFN- $\gamma$, interferon- $\gamma$; IL, interleukin; SSC, side-scattered light; FSC, forward-scattered light; APC, allophycocyanin; FITC, fluorescein isothiocyanate; PerCP, peridinin-chlorophyll-protein; Cy5.5, cyanine 5.5.

Further analysis of IL-22+ $\mathrm{T}$ cell subsets identified that there was a positive correlation between the proportion of Th22 and Th17 cells $\left(\mathrm{R}^{2}=0.4885 ; \mathrm{P}<0.0001 ;\right.$ Fig. $\left.1 \mathrm{I}\right)$. In contrast, no correlation between the proportion of Th1 cells and the 

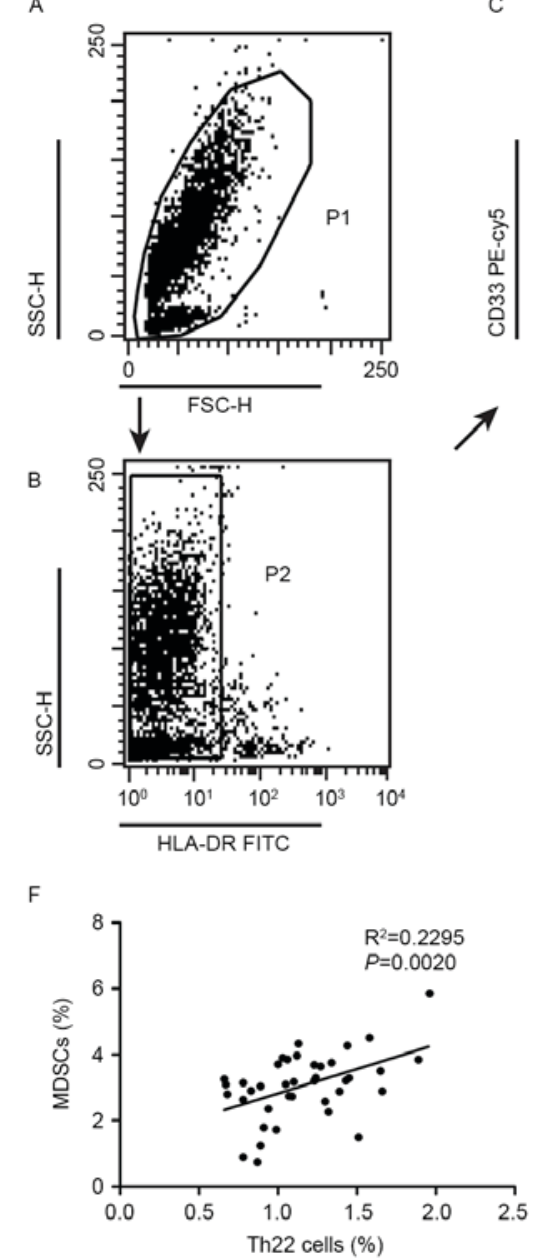

c
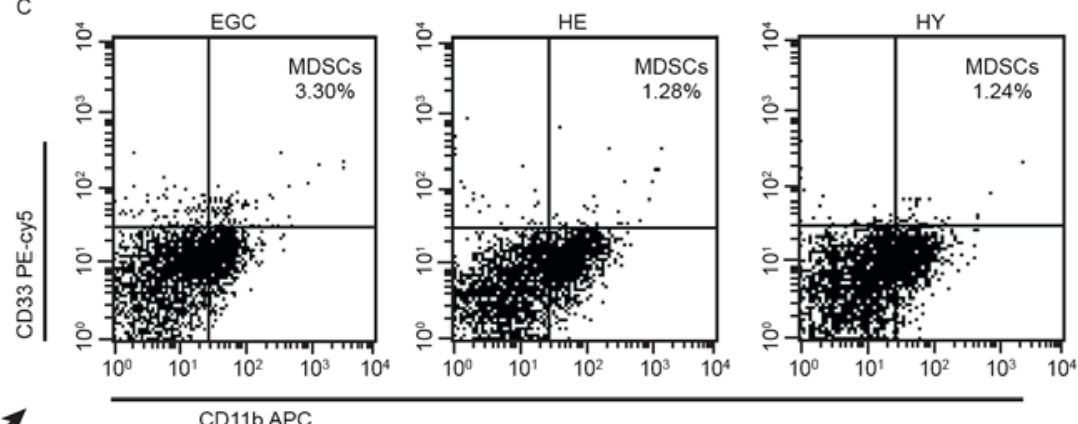

D

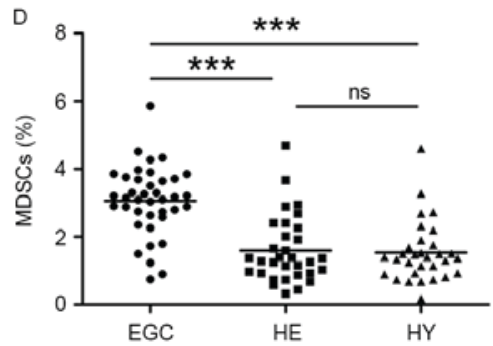

E

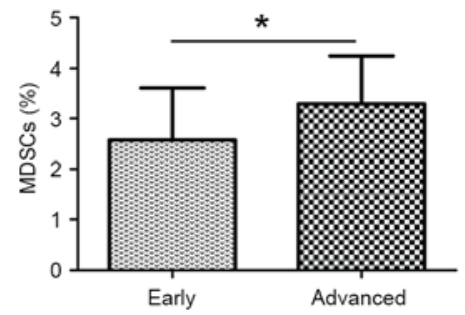

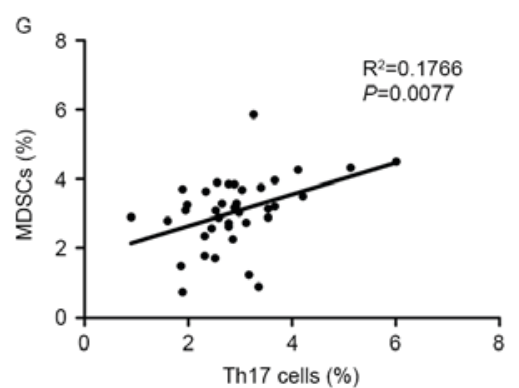

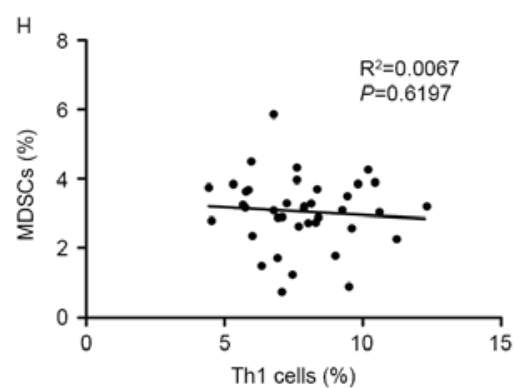

Figure 2. Flow cytometric analysis of MDSCs in peripheral whole blood from EGC ( $n=39), H E(n=32)$ and HY ( $=31)$. Gating routine in (A) P1 and (B) P2 successively for MDSCs (HLA-DR CD $33^{+} \mathrm{CD} 11 \mathrm{~b}^{+}$) subsets and (C) representative results of flow cytometric analyses for MDSCs in the three groups of subjects. The number of cells in EGC, HE and HY in P2 were 8,394, 8,004 and 8,224, respectively. (D) The proportion of MDSCs in the three groups of subjects. (E) The proportion of MDSCs in peripheral whole blood derived from patients with early $(\mathrm{n}=13)$ or advanced $(\mathrm{n}=26)$ gastric cancer. The association between the proportion of MDSCs and $(\mathrm{F})$ Th22, $(\mathrm{G})$ Th17 and $(\mathrm{H})$ Th1 cells in peripheral whole blood of elderly patients with cancer. ${ }^{*} \mathrm{P}<0.05,{ }^{* * * *} \mathrm{P}<0.001 . \mathrm{ns}$, not significant; MDSC, myeloid-derived suppressor cells; EGC, elderly patients with gastric cancer; HE, elderly healthy patients; HY, young healthy patients; HLA-DR, human leukocyte antigen-antigen D-related; CD, cluster of differentiation; Th, T helper; SSC, side-scattered light; FSC, forward-scattered light; PerCP, peridinin-chlorophyll-protein; Cy5.5, cyanine 5.5; APC, allophycocyanin; FITC, fluorescein isothiocyanate.

proportion of Th22 cells $\left(\mathrm{R}^{2}=0.0028 ; \mathrm{P}=0.5942\right.$; Fig. $\left.1 \mathrm{~J}\right)$ or Th17 cells $\left(\mathrm{R}^{2}=0.0012 ; \mathrm{P}=0.7271 ;\right.$ Fig. $\left.1 \mathrm{~K}\right)$ was identified.

Flow cytometric analysis of MDSCs in patients with gastric cancer and healthy controls. Additionally, the distribution of MDSCs was assessed using flow cytometric analysis. MDSCs were defined as HLA-DR $\mathrm{CD}^{-} 3^{+} \mathrm{CD} 11 \mathrm{~b}^{+}$. A significantly increased proportion of MDSCs was detected in EGC $(3.06 \pm 1.01 \% ; \mathrm{P}<0.001)$ compared with HE $(1.59 \pm 0.98)$ and HY $(1.53 \pm 0.88 \%$; Fig. 2A-D). Furthermore, the proportion of MDSCs was increased in patients with advanced disease relative to those with early-stage gastric cancer (3.30 \pm 0.94 vs. $2.58 \pm 1.02 \%$; $\mathrm{P}<0.05$; Fig. $2 \mathrm{E})$. No significant difference was observed in the distribution of MDSCs between HE and HY. Positive correlations were identified in the proportion of MDSCs and Th22 cells $\left(\mathrm{R}^{2}=0.2295\right.$; $\mathrm{P}=0.002$; Fig. $2 \mathrm{~F})$, and Th17 cells $\left(\mathrm{R}^{2}=0.1766 ; \mathrm{P}=0.0077\right.$; Fig. 2G). However, no correlation was identified between the proportion of MDSCs and that of Th1 cells $\left(\mathrm{R}^{2}=0.0067\right.$; $\mathrm{P}=0.6197$; Fig. 2H).
Plasma levels of IL-22, IL- 6 and TNF- $\alpha$ in patients with gastric cancer and healthy controls. Next, the plasma levels of IL-22, IL- 6 and TNF- $\alpha$ were examined in patients with gastric cancer and control subjects using ELISA. The plasma IL-22 level was significantly increased in EGC $(151.45 \pm 33.56 \mathrm{pg} / \mathrm{ml})$ compared with HE $(123.31 \pm 22.80 \mathrm{pg} / \mathrm{ml} ; \mathrm{P}<0.001)$ and $\mathrm{HY}(109.25 \pm 28.50 \mathrm{pg} / \mathrm{ml}$; $\mathrm{P}<0.001$; Fig. 3A). No difference in IL-22 levels was observed between HE and HY. In EGC, HE and HY, plasma IL-6 levels were $45.90 \pm 8.60,26.68 \pm 7.23$ and $18.17 \pm 7.95 \mathrm{pg} / \mathrm{ml}$, respectively $(\mathrm{P}<0.001$; Fig. $3 \mathrm{~B})$. Plasma TNF- $\alpha$ levels were increased in HE compared with HY $(38.66 \pm 12.94$ vs. $27.40 \pm 11.97 \mathrm{pg} / \mathrm{ml} ; \mathrm{P}<0.01)$ and were further increased in EGC $(59.70 \pm 17.38 \mathrm{pg} / \mathrm{ml} ; \mathrm{P}<0.001 ;$ Fig. $3 \mathrm{C})$. In addition, a significant difference in IL-22 plasma levels was observed between patients with advanced-stage and early-stage gastric cancer $(168.87 \pm 41.44$ vs. $131.92 \pm 33.93 \mathrm{pg} / \mathrm{ml} ; \mathrm{P}<0.01$; Fig. 3D). No significant differences between patients with Stage I-II and Stage III-IV gastric cancer regarding IL-6 levels $(44.62 \pm 10.44$ vs. $46.54 \pm 7.67 \mathrm{pg} / \mathrm{ml}$; Fig. $3 \mathrm{E})$ or TNF- $\alpha$ 

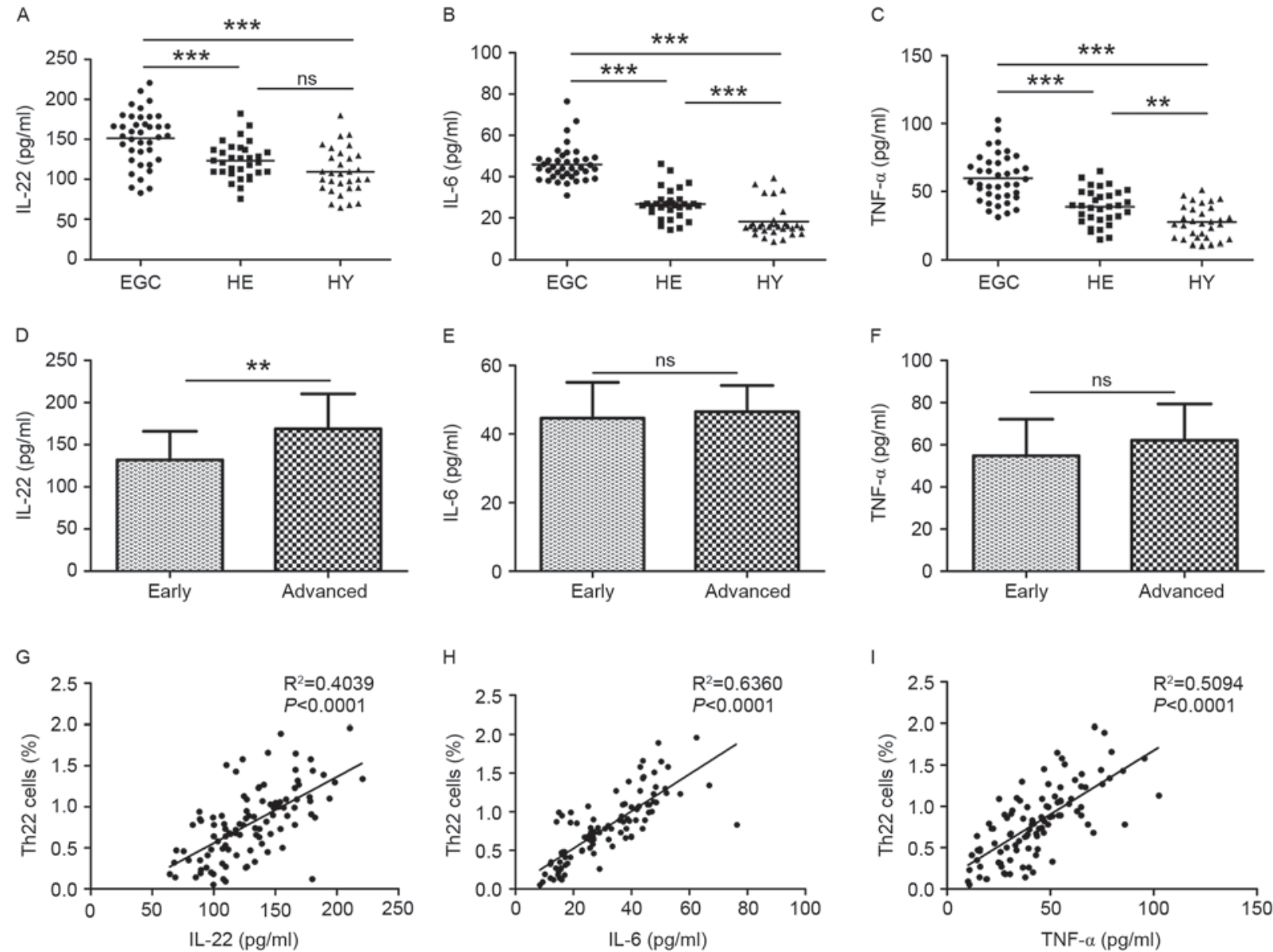

Figure 3. Plasma IL-22, IL-6 and TNF- $\alpha$ levels from EGC ( $n=39)$, HE $(n=32)$ and HY ( $n=31)$ were evaluated using ELISA. Plasma levels of (A) IL-22, (B) IL-6 and (C) TNF- $\alpha$ in the three groups. Plasma levels of (D) IL-22, (E) IL-6 and (F) TNF- $\alpha$ in patients with early (n=13) or advanced (n=26) stages of the disease. The association between the plasma (G) IL-22, (H) IL-6 and (I) TNF- $\alpha$ levels and the proportion of Th22 cells in peripheral whole blood of all subjects. ${ }^{* *} \mathrm{P}<0.01,{ }^{* * *} \mathrm{P}<0.001$. ns, not significant; IL, interleukin; TNF- $\alpha$, tumor necrosis factor- $\alpha$; EGC, elderly patients with gastric cancer; HE, elderly healthy patients; HY, young healthy patients; Th, T helper.

levels $(54.81 \pm 17.32$ vs. $62.16 \pm 17.23 \mathrm{pg} / \mathrm{ml}$; Fig. $3 \mathrm{~F})$ were observed. Positive correlations between proportions of Th22 cells and plasma IL-22 ( $\mathrm{R}^{2}=0.4039 ; \mathrm{P}<0.0001$; Fig. 3G), IL-6 $\left(\mathrm{R}^{2}=0.6360 ; \mathrm{P}<0.0001 ;\right.$ Fig. $\left.3 \mathrm{H}\right)$, and TNF- $\alpha\left(\mathrm{R}^{2}=0.5094\right.$; $\mathrm{P}<0.0001$; Fig. 3I) levels were observed.

Expression of IL-22 protein in tumor tissues. In order to determine whether IL-22 accumulates in tumor tissues, IL-22 protein expression in tumor sections obtained from 40 patients with gastric cancer was measured using immunohistochemical analysis. IL-22-positive cells were present at a significantly increased proportion within the tumor tissue and infiltrating lymphocytes around the tumor (Fig. 4A) when compared with normal gastric tissue. Consistently, normal gastric tissues contained no or only a small number of IL-22-positive cells (Fig. 4B). Furthermore, IL-22 protein expression was increased in Stage III-IV tumors compared with Stage I-II tumors (Fig. 4C and D). The IL-22 expression was further examined with respect to other clinicopathological characteristics of patients with gastric cancer. The presence of IL-22-positive cells was significantly associated with the depth of invasion and AJCC cancer stage $(\mathrm{P}<0.05)$, but not with sex, differentiation, lymph node metastasis or tumor size (Table I).

\section{Discussion}

Th22 cells, a subset of $\mathrm{CD}^{+} \mathrm{T}$ cells, are implicated in inflammatory-immune diseases including rheumatoid arthritis (22), Behcet disease (23), systemic sclerosis (24) and various types of cancer (25-27). The results of the present study identified that the fraction of peripheral Th22 and Th17 cells in HE increased when compared with HY, suggesting that the balance of Th22 and Th17 cells may alter during aging. Furthermore, the fraction of Th22 and Th17 cells was increased in EGC when compared with either HE or HY. In addition, the proportion of Th22 and Th17 cells was increased in patients with advanced gastric cancer when compared with patients with early-stage tumors. Indeed, these results are consistent with those of our previous study performed in colorectal cancer (12). IL-6, IL-1 and IL-23 are Th22 as well as Th17 cell polarization-inducing factors $(10,11)$, which may explain the observed positive correlation between Th22 cells and Th17 cells. Collectively, the results from the present study suggested that Th22 and Th17 cells may serve a role in the progression of gastric cancer in the elderly.

IL-22 is the primary functional factor of Th22 cells and is upregulated in several types of cancer $(28,29)$. In the present study, it was identified that IL-22 was increased in EGC 

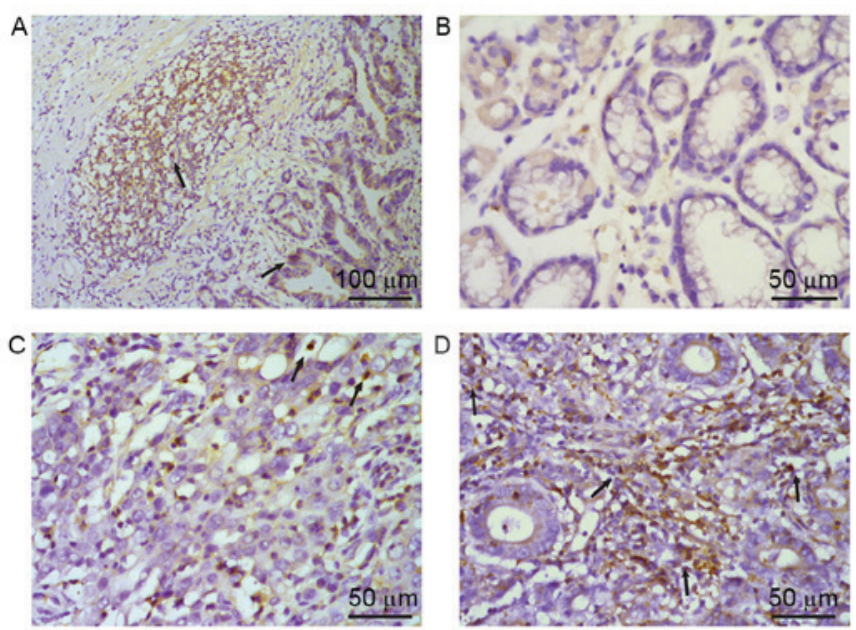

Figure 4. Expression of IL-22 protein in tissue specimens from patients with gastric cancer was evaluated using immunohistochemistry. IL-22-positive cells presented brown-yellow staining in the cytoplasm, as indicated by arrows. (A) IL-22 was mainly distributed in tumor cells and infiltrating lymphocytes around the tumor. IL-22 expression in (B) normal gastric mucous tissue and (C) tumor tissues in Stage I-II and (D) Stage III-IV gastric cancer. Hematoxylin staining of the same paraffin sections was used to distinguish between tumor cells and infiltrating lymphocytes. IL, interleukin

compared with HE and HY. In addition, IL-22 levels were identified to be associated with the progression of gastric cancer as demonstrated by the significant differences in IL-22 expression observed between distinct gastric cancer stages. These results imply that IL-22 may serve a role in gastric cancer progression in the aging and elderly. To further examine the possible association of IL-22 with other clinicopathological characteristics of elderly patients with gastric cancer, immunohistochemical analysis of IL-22 protein expression was performed in tumors and the corresponding normal tissue. The results identified that IL-22 was only expressed by intratumoral and infiltrating lymphocytes around the tumor, whereas IL-22 expression was rarely detected in normal tissue. These results suggest an autocrine mode of IL-22 expression in gastric cancer tissue. Additionally, these results support the previously established idea that tissue inflammatory and immune status may create a specific microenvironment that is able to promote the development of tumors (30). Furthermore, there was no significant difference in IL-22 plasma levels between HE and HY. A possible reason for this result is that Th22 cells also secrete other cytokines and therefore IL-22 expression levels do not fully reflect the role of Th22 cells in the regulation of inflammatory senescence (4-6).

A variety of cytokines and chemokines are able to cause an increase in the fraction of Th22 cells (31). Studies have demonstrated that increased levels of serum IL- 6 and TNF- $\alpha$ in elderly people are associated with cognitive discord and brain atrophy, leading to the proposal that these cytokines are aging inflammatory cytokines $(32,33)$. In the present study, plasma levels of IL- 6 and TNF- $\alpha$ were examined in EGC in comparison with HY and HE. Although the difference in IL-6 and TNF- $\alpha$ levels among the three groups was statistically significant, no difference was observed when these cytokine levels were compared with patients with early- and advanced-stage gastric cancer. These results are not in agreement with those of previous studies $(34,35)$. One of the possible explanations for this inconsistency may be the fact that gastric cancer progression is a result of a number of factors and a relatively small number of gastric cancer cases were analyzed in the present study. Furthermore, a positive correlation between IL-22, IL-6, and TNF- $\alpha$ levels and Th22 cells was identified in all three examined groups. These results are consistent with the fact that IL-22 is mainly secreted from Th22 cells, and that plasma IL- 6 and TNF- $\alpha$ levels are dependent on Th22 cells (14). Furthermore, TNF- $\alpha$ promotes the production of Th22 cells, which in turn secrete TNF- $\alpha(5,6)$. Therefore, this positive feedback may lead to continuously persistent chronic inflammation.

MDSCs are immunosuppressive cells that secrete several inflammatory factors under various physiological and pathophysiological states including cancer, chronic infection, trauma and graft-vs.-host reactions (36). Chronic inflammation and immune inhibition are mutually supportive (15). In the present study, the presence of peripheral MDSCs was analyzed in EGC, HE and HY, and it was identified that the proportion of peripheral MDSCs was significantly increased in EGC compared with HE. Furthermore, the proportion of MDSCs was increased in patients at a more advanced cancer stage. Nevertheless, no significant difference in MDSCs was observed between HE and HY. These results suggest that the increase in MDSCs is associated with the development and the progression of gastric cancer, but not with aging. A previous study has demonstrated that MDSCs were able to promote tumorigenesis via high expression of arginase-1, induction of nitric oxide synthase, and release of nitric oxide, free radicals and other reactive oxygen species to suppress the immune activity of T cells (37). On the other hand, MDSCs are able to promote expression of certain angiogenic factors, including vascular endothelial growth factor (38) and matrix metalloproteinases (39). It was identified that that MDSCs were positively correlated with Th22 and Th17 cells in elderly patients with gastric cancer and this regulatory axis was stronger for Th22 cells than for Th17 cells, indicating that both Th22 and Th17 cells are involved in the regulation of MDSCs. The potential underlying molecular mechanism may be that Th22 cells secrete cytokines, chemokines, acute reactive protein and other inflammatory factors together with several antimicrobial peptides including $\beta$-defensins, S100 family proteins and Reg family proteins (40). Furthermore, it will be important to exclude cells including $\mathrm{CD}^{+} \mathrm{CD}^{+} 9^{+}$and $\mathrm{CD} 6^{+}$cells from these analyses. In addition, since natural killer (NK) and natural killer T (NKT) cells may also produce IFN- $\gamma$, further studies are required to distinguish lymphocytes from $\mathrm{NK}$ and NKT cells.

Depending on the different organs and tissue microenvironments, Th22 cells and IL-22 may also have a protective role in cancer. For instance, in renal cell carcinoma, IL-22 inhibits tumor growth in a dose-dependent manner (41). In addition, IL-22 contributes to epithelial cell defense against Helicobacter pylori infection that is one of the major risk factors for gastric cancer (42). Thus, it remains to be determined whether Th22 cells and IL-22 exacerbate or ameliorate tumorigenesis.

In summary, to the best of our knowledge, the results of the present study demonstrate for the first time that the peripheral 
Th22 and Th17 cells as well as IL- 6 and TNF- $\alpha$ plasma levels increase with aging. These results suggest that peripheral $\mathrm{Th} 22$ and Th17 cells together with MDSCs and IL-22 levels are important markers of gastric cancer progression in elderly patients.

\section{Acknowledgements}

Not applicable.

\section{Funding}

The study was supported by a grant from Health and Family Planning Commission of Liaoning Province, China for the project of key medical specialties of Liaoning Province [No: 2015(111)].

\section{Availability of data and materials}

The datasets used and/or analyzed during the current study are available from the corresponding author on reasonable request.

\section{Authors' contributions}

$\mathrm{XC}$ and YW contributed to the experimental design and implementation, performed the experiments, drafted the manuscript, and performed data analysis. HZ conceived and designed the experiments, and modified the manuscript. JWa and XJ helped to collect the data. JWe and XW contributed to data analysis. All authors have read and approved the final manuscript.

\section{Ethics approval and consent to participate}

This study was approved by the Ethics Committee of The First Affiliated Hospital, Dalian Medical University (YJ-KY-FB-2014-42). Written informed consent was obtained from all participants or their families prior to obtaining the samples.

\section{Consent for publication}

Not applicable.

\section{Competing interests}

The authors declare that they have no competing interests.

\section{References}

1. Franceschi $\mathrm{C}$ and Campisi J: Chronic inflammation (inflammaging) and its potential contribution to age-associated diseases. J Gerontol A Biol Sci Med Sci 69 (Suppl 1): S4-S9, 2014.

2. Izano M, Wei EK, Tai C, Swede H, Gregorich S, Harris TB, Klepin H, Satterfield S, Murphy R, Newman AB, et al: Chronic inflammation and risk of colorectal and other obesity-related cancers: The health, aging and body composition study. Int J Cancer 138: 1118-1128, 2016.

3. Diller ML, Kudchadkar RR, Delman KA, Lawson DH and Ford ML: Balancing inflammation: The link between Th17 and rtegulatory T cells. Mediators Inflamm 2016: 6309219, 2016.

4. Eyerich S, Eyerich K, Pennino D, Carbone T, Nasorri F, Pallotta S, Cianfarani F, Odorisio T, Traidl-Hoffmann C, Behrendt $\mathrm{H}$, et al: Th22 cells represent a distinct human $\mathrm{T}$ cell subset involved in epidermal immunity and remodeling. J Clin Invest 119: 3573-3585, 2009.
5. Trifari S, Kaplan CD, Tran EH, Crellin NK and Spits H: Identification of a human helper $\mathrm{T}$ cell population that has abundant production of interleukin 22 and is distinct from $\mathrm{T}(\mathrm{H})-17$, $\mathrm{T}(\mathrm{H}) 1$ and $\mathrm{T}(\mathrm{H}) 2$ cells. Nat Immunol 10: 864-871, 2009.

6. Wolk K, Witte E, Witte K, Warszawska K and Sabat R: Biology of interleukin-22. Semin Immunopathol 32: 17-31, 2010.

7. Lim C and Savan R: The role of the IL-22/IL-22R1 axis in cancer. Cytokine Growth Factor Rev 25: 257-271, 2014.

8. Perusina Lanfranca M, Lin Y, Fang J, Zou W and Frankel T: Biological and pathological activities of interleukin-22. J Mol Med (Berl) 94: 523-534, 2016.

9. Zhang L, Wang T, Wang XQ, Du RZ, Zhang KN, Liu XG, Ma DX, Yu S, Su GH, Li ZH, et al: Elevated frequencies of circulating Th22 cell in addition to Th17 cell and Th17/Th1 cell in patients with acute coronary syndrome. PLoS One 8: e71466, 2013.

10. Anuradha R, George PJ, Chandrasekaran V, Kumaran PP, Nutman TB and Babu S: Interleukin 1 (IL-1)- and IL-23-mediated expansion of filarial antigen-specific Th17 and Th22 cells in filarial lymphedema. Clin Vaccine Immunol 21: 960-965, 2014.

11. Miossec P, Korn T and Kuchroo VK: Interleukin-17 and type 17 helper T cells. N Engl J Med 361: 888-898, 2009.

12. Li X, Wang Y, Han C, Li P and Zhang H: Colorectal cancer progression is associated with accumulation of Th17 lymphocytes in tumor tissues and increased serum levels of interleukin-6. Tohoku J Exp Med 233: 175-182, 2014.

13. Wu IC, Lin CC and Hsiung CA: Emerging roles of frailty and inflammaging in risk assessment of age-related chronic diseases in older adults: The intersection between aging biology and personalized medicine. Biomedicine (Taipei) 5: 1, 2015.

14. Duhen T, Geiger R, Jarrossay D, Lanzavecchia A and Sallusto F: Production of interleukin 22 but not interleukin 17 by a subset of human skin-homing memory T cells. Nat Immunol 10: 857-863, 2009.

15. ParkerKH,Beury DW andOstrand-Rosenberg S: Myeloid-derived suppressor cells: Critical cells driving immune suppression in the tumor microenvironment. Adv Cancer Res 128: 95-139, 2015.

16. Bueno V,Sant'Anna OA and Lord JM: Ageing and myeloid-derived suppressor cells: possible involvement in immunosenescence and age-related disease. Age (Dordr) 36: 9729, 2014.

17. Solito S, Falisi E, Diaz-Montero CM, Doni A, Pinton L, Rosato A, Francescato S, Basso G, Zanovello P, Onicescu G, et al: A human promyelocytic-like population is responsible for the immune suppression mediated by myeloid-derived suppressor cells. Blood 118: 2254-2265, 2011.

18. Lechner MG, Liebertz DJ and Epstein AL: Characterization of cytokine-induced myeloid-derived suppressor cells from normal human peripheral blood mononuclear cells. J Immunol 185: 2273-2284, 2010

19. Chatterjee S, Das S, Chakraborty P, Manna A, Chatterjee M and Choudhuri SK: Myeloid derived suppressor cells (MDSCs) can induce the generation of Th17 response from naive CD4+ T cells. Immunobiology 218: 718-724, 2013.

20. McGuire S: World cancer report 2014. Geneva, Switzerland: World health organization, international agency for research on cancer, WHO Press, 2015. Adv Nutr 7: 418-419, 2016.

21. Sobin LH, Gospodarowicz MK and Wittekind C: International union against cancer (UICC) TNM classification of malignant tumours, 7th edition. New York, Wiley-Liss, 2010.

22. Zhang L, Li JM, Liu XG, Ma DX, Hu NW, Li YG, Li W, Hu Y, Yu S, Qu X, et al: Elevated Th22 cells correlated with Th17 cells in patients with rheumatoid arthritis. J Clin Immunol 31: 606-614, 2011.

23. Aktas Cetin E, Cosan F, Cefle A and Deniz G: IL-22-secreting Th22 and IFN- $\gamma$-secreting Th17 cells in Behcet's disease. Mod Rheumatol 24: 802-807,2014.

24. Truchetet ME, Brembilla NC, Montanari E, Allanore Y and Chizzolini C: Increased frequency of circulating Th22 in addition to Th17 and Th2 lymphocytes in systemic sclerosis: Association with interstitial lung disease. Arthritis Res Ther 13: R166, 2011.

25. Huang YH, Cao YF, Jiang ZY, Zhang S and Gao F: Th22 cell accumulation is associated with colorectal cancer development. World J Gastroenterol 21: 4216-4224, 2015.

26. Kuang DM, Xiao X, Zhao Q, Chen MM, Li XF, Liu RX, Wei Y, Ouyang FZ, Chen DP, Wu Y, et al: B7-H1-expressing antigen-presenting cells mediate polarization of protumorigenic Th22 subsets. J Clin Invest 124: 4657-4667, 2014.

27. Tian T, Sun Y, Li M, He N, Yuan C, Yu S, Wang M, Ji C and Ma D: Increased Th22 cells as well as Th17 cells in patients with adult T-cell acute lymphoblastic leukemia. Clin Chim Acta 426: 108-113, 2013. 
28. Xu X, Tang Y, Guo S, Zhang Y, Tian Y, Ni B and Wang H: Increased intratumoral interleukin 22 levels and frequencies of interleukin 22-producing CD4+ T cells correlate with pancreatic cancer progression. Pancreas 43: 470-477, 2014.

29. Zhuang Y, Peng LS, Zhao YL, Shi Y, Mao XH, Guo G Chen W, Liu XF, Zhang JY, Liu T, et al: Increased intratumoral IL-22-producing CD4(+) T cells and Th22 cells correlate with gastric cancer progression and predict poor patient survival. Cancer Immunol Immunother 61: 1965-1975, 2012.

30. Axelrad JE, Lichtiger S and Yajnik V: Inflammatory bowel disease and cancer: The role of inflammation, immunosuppression, and cancer treatment. World J Gastroenterol 22: 4794-4801, 2016.

31. Sommer A and Fabri M: Vitamin D regulates cytokine patterns secreted by dendritic cells to promote differentiation of IL-22-producing T cells. PLoS One 10: e0130395, 2015.

32. Gorelick PB: Role of inflammation in cognitive impairment Results of observational epidemiological studies and clinical trials. Ann N Y Acad Sci 1207: 155-162, 2010.

33. Satizabal CL, Zhu YC, Mazoyer B, Dufouil C and Tzourio C: Circulating IL-6 and CRP are associated with MRI findings in the elderly: The 3C-Dijon study. Neurology 78: 720-727, 2012.

34. Zhao G, Zhu G, Huang Y, Zheng W, Hua J, Yang S, Zhuang J and Ye J: IL-6 mediates the signal pathway of JAK-STAT3-VEGF-C promoting growth, invasion and lymphangiogenesis in gastric cancer. Oncol Rep 35: 1787-1795, 2016.

35. Guo L, Ou JL, Zhang T, Ma L and Qu LF: Effect of expressions of tumor necrosis factor alpha and interleukin $1 \mathrm{~B}$ on peritoneal metastasis of gastric cancer. Tumour Biol 36: 8853-8860, 2015.

36. Highfill SL, Rodriguez PC, Zhou Q, Goetz CA, Koehn BH, Veenstra R, Taylor PA, Panoskaltsis-Mortari A, Serody JS, Munn DH, et al: Bone marrow myeloid-derived suppressor cells (MDSCs) inhibit graft-vs.-host disease (GVHD) via an arginase-1-dependent mechanism that is up-regulated by interleukin-13. Blood 116: 5738-5747, 2010.
37. Greten TF, Manns MP and Korangy F: Myeloid derived suppressor cells in human diseases. Int Immunopharmacol 11: 802-807, 2011.

38. Gerber HP, Olazoglu E and Grewal IS: Targeting inflammatory cells to improve anti-VEGF therapies in oncology. Recent Results Cancer Res 180: 185-200, 2010.

39. Melani C, Sangaletti S, Barazzetta FM, Werb Z and Colombo MP: Amino-biphosphonate-mediated MMP-9 inhibition breaks the tumor-bone marrow axis responsible for myeloid-derived suppressor cell expansion and macrophage infiltration in tumor stroma. Cancer Res 67: 11438-11446, 2007.

40. Zhuang Y, Cheng P, Liu XF, Peng LS, Li BS, Wang TT, Chen N, Li WH, Shi Y, Chen W, et al: A pro-inflammatory role for Th22 cells in Helicobacter pylori-associated gastritis. Gut 64: 1368-1378, 2015

41. Zhang F, Shang D, Zhang Y and Tian Y: Interleukin-22 suppresses the growth of A498 renal cell carcinoma cells via regulation of STAT1 pathway. PLoS One 6: e20382, 2011.

42. Dixon BR, Radin JN, Piazuelo MB, Contreras DC and Algood HM: IL-17a and IL-22 induce expression of antimicrobials in gastrointestinal epithelial cells and may contribute to epithelial cell defense against Helicobacter pylori. PLoS One 11: e0148514, 2016.

(i) () () This work is licensed under a Creative Commons CY NO ND Attribution-NonCommercial-NoDerivatives 4.0 International (CC BY-NC-ND 4.0) License. 